\title{
Animating the classroom: Pedagogical responses to internationalisation
}

Anita Mangan', Mihaela Kelemen ${ }^{1} \&$ Sue Moffat $^{2}$

${ }^{1}$ Keele Management School

Keele University

Keele

Staffordshire ST5 5BG

Corresponding author's email: a.m.I.mangan@keele.ac.uk

\author{
${ }^{2}$ New Vic Borderlines \\ New Vic Theatre \\ Newcastle-under-Lyme \\ Staffordshire ST5 0JG
}

\begin{abstract}
Internationalisation of the postgraduate classroom has become a feature of UK business schools, but traditional seminar-led learning often does not suit international students' learning needs. This article reports on a pilot project that used experiential drama workshops, held in a local theatre, as a response to the challenges created by internationalisation. As part of a collaborative auto-ethnography between two academics and a theatre practitioner, the article focuses on a theatre workshop where UK and Chinese MA Management students (the latter being the majority) were given full creative control to create a theatrical performance about the collapse of Enron. We outline how the project provided students with an opportunity to learn about ethical leadership through a series of experiential drama exercises and how it equipped the lecturers with tools and understandings that were subsequently used to teach leadership and critical management
\end{abstract}


studies in a more inclusive way. We conclude by discussing the benefits of using drama techniques to address internationalisation challenges, and urge business schools with a large international cohort to engage in a degree of pedagogical risk-taking in order to foster alternative ways of learning that are more inclusive and experientially based.

\section{Keywords}

Internationalisation, drama, experiential learning, ethical leadership, improvisation, ethnography

\section{Introduction}

Internationalisation has become an important part of UK universities' strategy, with many institutions expanding their international recruitment to earn additional income in an era of continuous budget cuts. Postgraduate recruitment is seen as a growth area and international students now make up a high percentage of postgraduate taught (PGT) programmes in the UK, with China being targeted as a particularly lucrative market (Turner, 2006). While internationalisation is championed by university management as a solution to the problem of falling university income, the delivery of the programmes is given less attention and is often assumed to be unproblematic. While many UK students will be familiar with discussion-led seminars common on PGT programmes, international students often struggle because their previous learning experiences are of different classroom pedagogies (Simpson et al., 2010; Currie, 2007; Turner, 2006). It is not surprising, therefore, that internationalisation of the classroom has become a growing concern (Crose, 2011), 
with particular attention being given to the high numbers of international students doing postgraduate taught (PGT) programmes in UK business schools.

As the number of international students in the classroom increases, often outnumbering UK students, universities are finding that traditional delivery methods do not suit the learning needs of international students (Crose, 2011; Turner, 2006; Currie, 2007). At its most extreme, all parties involved in PGT programmes experience a sense of crisis: international students feel isolated and question the wisdom of deciding to study abroad, UK students complain that international students do not contribute in class, while the lecturers discover that tried and trusted teaching methods are no longer effective. Finding ways to address this crisis is imperative, given that internationalisation continues to be a high priority for universities.

This article reflects on a project that uses experiential drama techniques as a pedagogical response to the internationalisation of the postgraduate classroom. It was devised in response to student feedback about internationalisation and two of the authors' concerns about the difficulties they were experiencing when teaching topics such as organisational power, politics, leadership and ethics to MA Management students who had little work experience and were unfamiliar with the UK university system.

Such learning and teaching challenges have been widely acknowledged by the internationalisation literature (Crose, 2011; Turner, 2006; Sun and Richardson, 2012) and there has been a growing call for programmes to move beyond traditional approaches and to adapt to the needs of international students (Kelly and Moogan, 2012; Valiente, 2008). Drama techniques are often used to tackle problematic situations in organisations with the goal to elicit a range of reactions from multiple organisational actors, from experiencing 
individual catharsis to creative problem solving (Meisiek, 2004). This inspired us to design and conduct a series of drama workshops to tackle some of the challenges we faced in the classroom.

We worked in collaboration with an award winning theatre which has a long tradition of working with marginalised communities and individuals from all walks of life. The theatre states in their published materials that their way of working 'gives voice' to individuals and groups who sit on the margins of the society, and in so doing creates environments where traditional hierarchies and barriers are dissolved, new dialogues are possible and different useful relationships formed. As verbal and non-verbal activities were given equal importance in the workshops, issues of voice became less important, allowing students to participate in more embodied ways 'by doing' rather than just 'by talking'. This approach 'animated' the students and even those who were usually very quiet in the classroom found ways to express their views and contribute fully to the exercises.

The article is organised as follows. It begins by discussing the literature on the internationalisation of postgraduate education. It then provides an overview of the use of drama as a teaching and learning technique and outlines the rationale for the way we designed and conducted our drama workshops. This is followed by an account of one of the workshops, where students moved from improvisational exercises to creating a series of non-verbal presentations (i.e., performances) about the Enron case study (Tourish and Vatcha, 2005; Boje et al., 2004; 2006; Boje and Rosile, 2003) which they had initially studied in the classroom. The article concludes by discussing the benefits of using drama techniques as a way of managing internationalisation of the classroom and reflects on how the study influenced us as lecturers. 


\section{Internationalisation of the postgraduate classroom}

Definitions of internationalisation are vague. For some universities, it means offering learning materials with an international flavour, while for others, it translates into increased numbers of international students (Elliott and Robinson, 2012). In the case of UK business schools, internationalisation refers to students from outside the EU who are charged higher fees. In response to funding cuts, UK universities are pursuing internationalisation agendas, with China as the main market for UK PGT programmes (Turner, 2006). In practice, Chinese students make up the majority of international students on UK PGT programmes. When international students outnumber UK students, it also means that the majority of students in the classroom are Chinese (see: Currie, 2007; Sun and Richardson, 2012; Simpson et al., 2010).

The positive view of internationalisation is that it enables students to take advantage of what globalisation has to offer and prepares them to work with people from a range of cultures. Too often, however, internationalisation leads to a 'learning shock' (Griffiths et al., 2005) where international students are disoriented, confused and upset by unfamiliar teaching methods or by the gap between their expectations and the reality of the programme (Elliott and Robinson, 2012). The learning shock can also be experienced by UK students who find themselves in a minority in the classroom. The following review of recent literature on international students' experience of Western postgraduate education highlights what are seen as key problem areas. Much of this literature relates to Chinese students on standard UK PGT programmes, with particular emphasis given to MBA programmes. 
Currie (2007) defines the predominant pedagogical model used in UK business schools as 'Anglo-American', arguing that it organises learning in constructivist, rather than behaviourist, terms. Thus, unlike the behaviourist approaches to education, where learning is understood as being transmitted from lecturer to student, the majority of UK PGT programmes emphasise the co-creation of knowledge (Light and Cox, 2001). Classroom activities thereby include techniques such as student-led seminar discussions, exploration of multiple viewpoints, critical analysis and debates. As Currie (2007) notes, students are expected to be proactive learners in this environment and to be vocal participants in the classroom and during group work. In contrast, Valiente (2008) outlines a 'Confucian' pedagogy, familiar to many East Asian students, that priorities memory and rote learning as a key feature of the learning process. The differences between these pedagogical approaches are often deeply embedded in the learning environment and rarely reflected upon by institutions and individual academics (Currie, 2007; Simpson et al., 2010; Turner, 2006).

The result is that international students report experiencing marginalisation (Simpson et al., 2010; Turner, 2006), anxiety (Currie, 2007; Valiente, 2008) and culture shock (Kelly and Moogan, 2012) in the classroom as they struggle to adjust to new teaching and learning methods, language barriers and an emphasis on critical analysis. Research suggests that Chinese students, in particular, experience difficulties when asked to engage in individualised debate in class (Simpson et al., 2010; Currie, 2007). Debate and analysis can cause anxiety (Turner, 2006) because it requires students to query the teacher and their classmates in a way that many of them are unfamiliar and uncomfortable with. As a result, Chinese students are often characterised as passive learners, with the underlying 
(normative) assumption that UK students are more active learners. However, what might be labelled as 'passive' could be the result of cultural misunderstanding, linguistic difficulties or lack of confidence (Valiente, 2008). Furthermore, caution should be exercised when characterising 'the Chinese learner', because students' approaches to learning are not just culturally determined (Sun and Richardson, 2012) but also influenced by the social situation (Stead and Elliot, 2013), individual expectations and understandings of what an ideal student is. Moreover, as can be seen from some of the labelling and stereotyping, the studies sometimes assume that national 'types' exist and that students from a particular region can be treated as an undistinguished, homogenised mass.

Language ability is a sensitive issue (Turner, 2009), with Cheng (2013) highlighting the power relations that exist within student groups, where international students feel powerless and undervalued when working with native English speakers. As Simpson et al. (2010) note, unequal power relations are frequently overlooked when thinking about the international students' experience of Anglo-American pedagogy. This creates a situation where 'home' students are set up as the 'norm' and international students become 'the other'. These cultural norms can also be problematic, as teacher-led discussions can easily reproduce cultural insiders and outsiders (Turner, 2009) by privileging students who are fluent, confident speakers and familiar with the local classroom norms. Thus, in the classroom 'othering' becomes a constant issue; cultural differences can exacerbate misunderstandings leading to students becoming withdrawn and/or labelled as free-riders because they do not communicate well (Gabriel and Griffiths, 2008). At the level of student interaction, students can be inclined to create unfavourable national stereotypes of each other: UK students characterise their Chinese classmates as having poor English skills, being unwilling 
participants in class, slow and needy, while Chinese students see the UK students as domineering, aggressive, intolerant and unfriendly (Turner, 2009). The stereotypes would seem to develop because there is little opportunity for socialisation and cultural exchange in tightly scheduled, modularised PGT programmes. On year-long programmes, where there is little scope for ideas to emerge at a leisurely pace, UK students can become ethnocentric, labelling their international classmates as free-riders (Currie, 2007; Gabriel and Griffiths, 2008) because they do not contribute to class discussions and group assignments. This often leads UK students to assume that they are 'carrying' the international students. As a result, international students become marginalised during group work (Gabriel and Griffiths, 2008) or have their contribution reworked by home students because it does not conform to local, implicit understandings of what is required (Cheng, 2013).

There is frequently a disjoint between students' expectations and what the PGT programme will deliver (Elliott and Robinson, 2012). Turner's (2006) year-long study highlights the emotional stress and lack of confidence experienced by Chinese students on a taught MA programme, suggesting that many Chinese students spend the first semester acclimatising and only fully engage with course material in the second semester. Students may take a long time to make the transition from one pedagogy to another (Kelly and Moogan, 2012; Currie 2007). Because the UK institutions and individual academics rarely reflect on their own pedagogical biases (Currie, 2007; Simpson et al., 2010; Turner, 2006), in order to make a successful transition, international students need to learn how to negotiate specific discourses of knowledge and socio-political contexts (Cheng, 2013). Thus, while some international students manage to develop coping mechanisms (Cheng, 2013), others' learning strategies remain unchanged (Turner, 2006) and they struggle throughout their PGT programme. 
Responses to these issues are varied. There is a growing call for taught PG programmes to move beyond the traditional approaches and to adapt to the needs of the international students (Kelly \& Moogan, 2012; Valiente, 2008). Others stress the need to create better integration between UK and international students (Currie, 2007). Similarly, Turner (2006) advocates greater socialisation of international students, arguing that they need to understand the 'cultural epistemology of their day-to-day experiences' (47) in order to appreciate the specific pedagogical requirements of a UK PGT programme. Sun and Richardson (2012) argue that Chinese students need greater support structures in order to develop deep learning strategies, while Turner (2006) recommends intensive mentoring of international students by staff on these programmes. Turner notes, however, the emotional drain she experienced during the research, as she emerged as a trusted mentor to the student participants. Thus, although Turner's suggestion would be welcomed from a student perspective, it could have the unintended consequence of increasing the emotional labour required of academic staff on PGT programmes. What seems clear is that these requirements are responses to inequalities that are deeply embedded in programme structures, with Western pedagogical and epistemological biases rarely being reflected upon (Turner, 2006; Currie, 2007). As Turner (2009: 243) notes, however, while the literature is beginning to consider 'implicit local norms that silently privilege home students over others', there is little agreement on the degree of institutional bias (structure) and responsibility of individual learners (agency) in any given classroom. Thus, solutions or alternative approaches to teaching an international classroom in an inclusive manner are in short supply.

To summarise then, the internationalisation literature points to myopia in Western management education that focuses on a pedagogical approach that many international 
students find alienating. Research has explored the isolation experienced by international students and the difficulties they experience when making the transition from 'passive' to 'active' learning. Various solutions are suggested, ranging from greater socialisation and integration of students to structural changes. The overwhelming impression is that of a crisis in the classroom, with students and lecturers searching for ways to make sense of a new teaching and learning experience. The next section explores the use of drama in the classroom, as well as considering improvisational theatre as a response to the crisis.

\section{The use of drama in management education}

In recent years, drawing on drama techniques has become increasingly popular in management education (Moshavi, 2001; Lesavre, 2012). Research in this area includes practical advice on using drama in the classroom, to accounts of how the use of drama as a pedagogical tool can benefit students. Theatre is seen to build inter-personal skills (Stager Jacques, 2013), promote creative problem-solving (Moshavi, 2001), acknowledge neglected strengths (Feagan and Rossiter, 2011) and reduce hierarchy in the classroom (Lesavre, 2012). Moreover, it is argued that theatre exercises are suitable for different learner types (Corsun et al., 2006) because they encourage experiential learning (Huffaker and West, 2005). Drawing on theatrical practice allows students to gain emotional, as well as intellectual knowledge, giving the opportunity for holistic learning (Elm and Taylor, 2010).

The most common drama technique used in education is based on role-play. Baruch (2006) focuses on lecturers' use of role-play as a teaching aid, presenting a model of various metaphorical masks a lecturer can adopt, loosely arranged around two axes: interactive/passive and thinking/feeling. The framework include roles such as coach, sales- 
person, stand-up comic and preacher, each of which can be used in different classroom situations to enhance learning. Role-play is not guaranteed to succeed, however, as there are contingencies to consider such as class size, the students' maturity and level of experience. Much can also rest on the individual lecturer's level of skill and ability to act in class. A more common approach is to focus on engaging students in role-play, whether by acting out existing scripts (Prichard, 2009) or by improvising different scenarios (Moshavi, 2001) to prompt class discussions or develop practical skills.

Although arts and management are now so deeply entwined as to constitute a distinct field of study (Meisiek and Barry, 2014), drama techniques such as role-play should not be seen as simply another tool in the arsenal of managerial techniques and practices to be transmitted to students. Many discussions of drama and management veer into functionalist approaches where theatre is seen as an organisational resource, one that management can deploy in order to exert some form of control over employees. As Beirne and Knight (2007) argue, this can suppress creativity and dissent because participants are steered by the strong managerial vision behind the dramatic work. They argue that, at its most extreme, this constitutes a colonisation of the theatrical form by management, whereby theatre is reduced to just one more pedagogical tool deployed as a novelty. In response, they advocate drawing on radical theatre traditions which allow students to develop their own voices and explore ideas in a creative, safe environment.

As such, management education could benefit from the emancipatory power of drama. Sutherland (2012: 40) argues that arts-based methods make possible the development of aesthetic workspaces in which management learning is de-routinised and aesthetic reflexivity becomes the norm, leading to improved capacity for leaders to 'responsibly and 
ethically engage with the complex, dynamic, chaotic and highly subjective, interactional environments of contemporary organisational life'. Arts-based methods help leaders to see more and see differently (Barry and Meisiek, 2010) and to develop self-knowledge and knowledge of the others that would not be possible via traditional developmental methods. The resulting aesthetic reflexivity allows leaders to apprehend tacit knowledge (cf Taylor and Ladkin, 2009) and to appreciate leading as a craft (Taylor and Ladkin, 2014). The meditative and contemplative element has also come to prominence in arts-based methodologies, with proponents arguing that through art making, leaders become more holistic people and can express themselves more freely and creatively, unburdened by organisational codes of behaviour and related power structures (Cunliffe, 2009).

For those who encounter drama as a pedagogical tool for the first time, a common assumption is that it is synonymous with role-play. There are, however, a wide range of alternative approaches available based on improvisational, experiential techniques. Many of these are inspired by the forum theatre of Boal (2008), who wanted to radicalise audiences by transforming their experience from passive spectacle to active engagement with the material on stage. He coined the phrase 'spect-actor' to encapsulate a theatrical process where the audience are actively encouraged to query the material being presented, debate key issues and present a range of solutions, which are then enacted on stage. Boal's work has been adapted by practitioners and researchers to suit local contexts, with the express aim of encouraging reflexivity by defamiliarising common situations in order to raise debate and facilitate learning (Beirne and Knight, 2007; Pässilä et al., 2013).

The work of Boje et al. (2003) on theatre and metaphor opens up the possibility of using theatre to unearth individual motives and meanings as well as the political structures in 
which they are embedded. For Boje and colleagues, organising is simultaneously 'like theatre' in that organisational actors engage in on and off stage performances, as well as 'being theatre' for much of organisational life is literally dramatic and theatrical. They have used this approach in a series of studies on the collapse of Enron (Boje et al., 2004; 2006; Boje and Rosile, 2003).

In one sense, the improvisational (improv) approach is similar to the experiential learning linked to outdoor management development (OMD). It has several features in common with OMD, including a novel environment, an element of risk, flexibility of activities to match participants' needs and the importance of facilitation to translate the experience into lessons learned (Ibbetson and Newell, 1999; Irvine and Wilson, 1994; McEvoy and Buller, 1997). Indeed, Broderick and Pearce (2001) suggest that OMD activities can be brought indoors by replacing the outdoor activities with educational drama elements. There is debate, however, as to the value of the OMD learning experience, with critics arguing that it is over-reliant on anecdotal evidence (Irvine and Wilson, 1994) and 'happiness' evaluations rather than evidence of learning (Ibbetson and Newell, 1999). However, as Hinchliffe (2000) notes, $\mathrm{OMD}$ is a different kind of learning, one that cannot be easily translated into 'management speak'. For Hinchliffe, OMD incorporates embodiment, play and experimental learning. He argues that these require a shift away from functionalist evaluations of OMD as a way to create better corporate workers, to a broader appreciation of their power to sensitise us to our embodied existence and the ways in which knowledge can emerge in unpredictable ways. This is a similar argument to that which Taylor (2012) makes about craft skills in organisations. 
It is this embodied, exploratory aspect of OMD that we find most relevant for our discussion of the role of improv, because we are more concerned with classroom learning, rather than workplace training. Some important features of the improv approach is that it empowers students (Monks et al., 2001) by disrupting traditional classroom hierarchies and creating a space for open, non-judgemental communication (Moshavi, 2001). This enables students to construct meaning for themselves through interaction with their peers (Corsun et al., 2006; Gagnon et al., 2012). Discussion can evolve in a non-linear fashion (Huffaker and West, 2005), with students learning skills of reciprocity, collaboration and group harmony (Stager Jacques, 2013).

Given the benefits of an improvisational approach, drawing on experiential drama techniques would seem like a useful way of responding to the challenges posed by the internationalisation of the PGT classroom. In the case study that follows, we analyse one such experiment, where students on an MA programme in Management took part in a series of three full-day theatre workshops.

\section{Background}

The case study reflects upon a small teaching innovation project undertaken in a UK management school where over $80 \%$ of the PGT cohort is international and $90 \%$ of the international students are Chinese. Inspiration for the project came from two sources: the students and a serendipitous conversation between the authors. In the first instance, student feedback received during a staff-student liaison meeting identified three areas of concern: integration, classroom participation and cultural differences. The student group, which included home and international students (mostly Chinese), echoed many of the 
themes discussed in the literature (e.g. Currie, 2007; Gabriel and Griffiths, 2008). Students expressed concern that there was little interaction between the UK and international students and that the latter were not contributing in class. Moreover, the students made broad statements about the cultural differences between the students, reinforcing negative stereotypes about each other (Turner 2009). The second source of inspiration was a chance conversation between the authors who, for a number of years, have been involved in joint community-based participatory research that used theatre-based techniques. The two academics were complaining to the theatre director (third author) how hard it was to teach ethics and leadership to international students: the response was 'why not bring them to the theatre to try out some improvisational techniques!'

The workshops were intended as both a response to the needs of international students (Kelly and Moogan, 2012; Valiente, 2008) and an innovative approach to management education (Prichard, 2009). Firstly, we hoped to promote greater integration and socialisation of the student cohort, while giving them opportunities to think about the module content in new ways. Secondly, rather than creating specific learning objectives, we were interested in promoting a broader understanding of education that encouraged a reflective approach to future endeavours, drawing on the theatre's nationally recognised record of empowering marginalised communities and examining quality of life issues. Thirdly, we hoped to acquire new tools and understandings that could be brought back into the classroom in order to teach critical management topics in a more effective way. Key to achieving these aims was the combination of academic and theatre skills. This was facilitated by the ongoing relationship between the authors (two academics and one theatre practitioner) who had been working together on various sponsored research projects and had a trusting relationship in place. 
Another important factor was the culture and ethos of the theatre, which has a long history of engaging with marginalised individuals and communities, winning national awards for its work and working in partnership with a range of local and national government departments, third sector organisations and universities. The theatre's main aim is to change lives and this is delivered through its main productions as well as through specific theatre outreach projects. The theatre has developed a long-standing reputation for delivering artistically ambitious, powerful interventionist theatre projects, building on fifty years of a documentary and participatory theatre tradition. As such, it develops projects either in direct response to the needs of the local communities or as commissioned around specific themes. The theatre takes the work out to places where it will have the maximum impact but also brings individuals into the theatre where participants will find a creative, accepting and supportive environment and where they can explore their lives, contribution to local community and in so doing play their part as active and responsible citizens (web link will be added).

Students were brought to the local theatre for a series of three full-day residential workshops, led by Author Three, an experienced theatre director, and two other theatre practitioners. The first two workshops were timetabled to take place in Week 5 (October) and Week 11 (December) of the first semester, while the final workshop was timetabled for Week 3 in the second semester (February). The workshops took place on a Wednesday, as the relevant modules ran in the morning and there were no scheduled classes on Wednesday afternoons. Each workshop explored a specific theme (power and control, organisational culture and ethical leadership, respectively) and was scheduled to happen after students had attended the module seminar on the topic. 
Each workshop was timetabled in a similar fashion. The day began and ended in the university. We would gather with the students in the university reception in the morning, get a bus to the theatre and be ready to start work immediately. The bus brought them back to campus in the evening. As noted in the previous section, it was important to bring the students off-campus to the theatre, because it broke their expectations about how to behave in the classroom (Lesavre, 2012) and disrupted existing power relations (Currie, 2007). Each day began with warm-up exercises, usually an energetic 'name game' designed to get people moving around, gaining confidence and learning the ground rules for the day. All activities after that were linked to specific issues raised by the readings. Typically, the students, the academics and theatre practitioners (hereafter 'the group') would complete two warm-up exercises, plus two or three short activities before lunch. The lunch break lasted about an hour and students were completely free during this time. We used the lunch break to discuss how the day was going and what emergent themes and topics we should develop in the afternoon. After lunch, the group would be given a longer more complex task which took the entire afternoon.

Although improvisational (improv) workshops seem to happen spontaneously, thorough preparation was important (Monks et al., 2001) both for students and staff. Two key readings were set for each theme, drawing on trusted teaching materials that the academics had used for several years. Students were expected to study them in advance, as they would for a tutorial or seminar on the topic. The theatre director then used the readings to create a series of exercises, games and problems for the group to engage with. She commented: 
I was delighted to see that the attention I would pay to a piece of work such as Shakespeare could be applied to academic papers, and would bring about moving and exciting results played out not by professional actors, but by equally talented management students (Reflective diary, Author Three).

For example, students learned about disciplinary power (Foucault, 1977) in the lecture on power and control. During the workshop, they played a game called 'Prisoners and Guards' which explored the metaphor of the panopticon through the activity of trying to 'escape' from their guards. The group explored wicked problems (Rittel and Webber, 1973) in the 'Human Knot' (where the group randomly joins hands and then tries to untangle to form an unbroken circle, see Picture 1) and emergent leadership in 'Spot the Leader' (where the group was told that the director had picked someone to be a leader and they had to spot who it was; the catch being that nobody had been chosen).

Debriefing was an important feature of the workshop timetables. At various points during the workshops, mid-activity and at the end of each exercise, we asked the students to reflect on the exercises and to relate them to their academic learning and practical experiences, facilitating collaborative learning (Light and Cox, 2001; Valiente, 2008). As the OMD literature also notes, expert facilitation is a key part of the learning process (Ibbetson and Newell, 1999; Irvine and Wilson, 1994). Thus every workshop ended with a general discussion and debriefing, led by the theatre director, which encouraged reflection on both the process of learning and significant events during the workshops. It was during these final discussions where we often saw reflection and learning taking place. As an extract from Author One's field diary notes: 
You could see TO (international student) almost thinking out loud as the day progressed. A few times during the first workshop she looked like she was about to have an epiphany. It happened during the final circular discussion. [Author Three] was wrapping things up when TO jumped forward, breaking out of the circle, and cried 'I want to say something'. I can't remember exactly what she said because I was in the circle too and it happened so quickly that by the time I got on the bus, it was gone from me. My memory of it was that she synthesised all the material we'd covered during the day and managed to link it to some basic ideas about power and control.

The Theatre Director commented:

It was wonderful to see that the playfulness required to benefit from all these exercises manifested clearly in the students who came alive in playing these games showing not only their intellectual understanding of the topics but also their ability to move between theory and practice with such ease and having so much fun (Author Three).

Breaking expectations was important (Feagan and Rossiter, 2011) in order to disrupt learned classroom behaviours and create a space for new forms of learning. In the theatrical space, traditional classroom hierarchies are disrupted as 'all participants are beginners' (Lesavre, 2012: 246), including the lecturers. Interestingly, however, the students automatically reproduced classroom hierarchies when they arrived for the first workshop. While the lecturers and theatre practitioners were greeting each other, the students automatically began to set out rows of chairs for themselves at the far side of the studio space and sat down with notebooks out and pens at the ready. In subsequent workshops, however, students dumped bags and coats in the audience area and ran onto the stage. 


\section{Methodology}

In terms of methodology, our approach to the project is a collaborative auto-ethnography (May and Pattillo-McCoy, 2000) between two academics and a theatre practitioner, which draws on our personal narratives (cf Daskalaki, 2012; Stoudt, 2009), field diaries and conversations about the project. The project presented us with an opportunity to reflect on the liberating experience of fusing drama and teaching, yet it has also left us with conflicting emotions about our experience; a subject which we will return to in the final section of the paper.

The project received ethical approval from the university's Ethics Review Panel, part of which required the academic authors to give special consideration to issues of power and vulnerability. The panel was concerned that the academics' blurred role as lecturers and researchers would make the students feel pressurised into taking part in evaluative sessions. We were required to use an intermediary both to obtain student consent and to run the focus group. Information sheets and consent forms, approved by the Ethics Review Panel, were distributed to students prior to the project starting.

As critical scholars, concerned with issues of power and ethical leadership, we were also anxious to disrupt the power imbalance between students and researchers. To this end, we explained the project in full at the start of the academic year and again before each workshop. Students were informed that we had to submit a project report for the university and that we wanted to publish an academic paper based on the project. We also explained our note-taking process. This information was also included in the consent forms and information sheet. In addition, when Author Three was first introduced to the students, she emphasised the theatre's tradition of inclusivity, creating a theatre 'company' of all those 
present (students, academics and theatre practitioners - 'the group'). During the workshops, people were constantly referred to as members of the company, or participants, rather than students and teachers/researchers. We remained conscious of our privileged position throughout the project, but were also aware of the paradox that while we might be anxious to disrupt hierarchies, some of the students might not be as keen. While we would not claim to have eliminated power relations (Foucault, 1977), in what follows we outline the methodological steps we took to run the workshops in an egalitarian manner.

As lecturers and theatre practitioners, we were responsible for organising the workshops, but we also were active participants in the improv exercises; for us, disrupting learned behaviours included abandoning our own status as 'experts' and claiming no special privileges. Thus, for the first workshop, field notes and reflective diaries were compiled immediately after the first workshop by the first and second authors, but no notes were taken during the workshop itself because to do so would have taken the academic authors out of the improv activities and re-established hierarchical power relationships of students/lecturers and actors/audience. For the second and third workshops, with agreement from the students, the first and second authors took turns to participate and observe, with field diaries written up at the end of the day. Observations consisted of handwritten notes and photographs of activities. Students often asked to see what we were writing down and added their own comments on what they observed happening. Further data was collected as part of the routine module evaluation forms. However, although this feedback was overwhelmingly positive ('profound', 'creative', 'interesting and useful'), the observations were pithy at best and not sufficient to use in a paper. Similarly, the feedback focus group, which was organised and run by intermediaries, only had two participants. Their contributions included feedback they collected from their peers. This was valuable for 
our internal evaluation of the project, but insufficient for an academic paper. Moreover, as none of the students wished to be involved in writing a paper on the project, the data presented here is drawn solely from our reflective diaries and field notes.

In terms of analysis, all three authors began sense-making activities (Weick et al., 2005) while planning the first workshop and continued to reflect on our interpretations of events throughout the short project. Informal debriefing sessions were held after each workshop where the authors discussed key events, shared observations and discussed tentative conclusions about how the workshops were working towards the project's aims. The authors also reflected on how their relationships with the students were changing over the course of the project, commenting on how students were beginning to break out of their 'national' groups and their growing confidence, both at the theatre and in class. As previously mentioned, all three authors have been working together for a number of years and so we have continued to discuss the project over two years since it ended. To develop our ideas for this paper, we shared our field diaries and the theatre director's preparatory notes, commented on each other's interpretation of events and discussed how the theatre experience profoundly changed our perceptions of international students' abilities and our teaching practices.

In what follows we present data from our reflective diaries and field notes and the third author's preparatory notes to present the story of a full-day workshop which explored ethical leadership issues. We chose this workshop, the final one in the project, because it was the first workshop where the students were asked to create a performance piece on their own, based on the techniques they learned in the previous workshops, as well as their knowledge of the Enron case, which they had studied in the first semester (in a session on 
'organisational culture' in Critical Management Studies) and again in the second semester (the 'ethical leadership' section of the Leadership module). Activities in the previous workshops were strongly guided by theatre practitioners, but in this final workshop, students had complete control over the creative process and it was the first occasion where they were explicitly asked to fuse their theoretical and experiential drama learning. This is what makes the final workshop an interesting case study because we had the opportunity to observe how students articulated their theoretical learning via experiential drama exercises. We present vignettes from our diaries and notebooks to articulate examples of students engaging in experiential learning and demonstrate how our understanding of the students' abilities transformed over the course of the workshops.

\section{The workshop: Performing and reflecting on the meaning of ethical leadership}

This workshop was the last of three full-day experiential drama workshops that had taken place over five months, starting in the middle of the first semester. At this stage, everyone was used to the workshop routine. As one of our diary entries notes:

Students seemed to be quite relaxed this morning. There wasn't the 'pre-exam anxiety' of the first trip, or the buzz of anticipation from the second. Maybe they're more confident or maybe they're tired because exams finished last week and now they're straight into a new set of modules (Author One).

The theme of the workshop was ethical leadership and in preparing for it, the authors drew on lecture, seminar and reading material that students had already covered in class (Tourish and Vatcha, 2005; Grint, 2005; 2007; Kelemen and Peltonen, 2001). As discussed in the section on internationalisation above, the international students' participation in the 
classroom debates had been muted, despite the lecturer's efforts. The theatre director and theatre practitioners read the set texts and devised a series of games and exercises that drew on key theories from these texts such as wicked/tame problems, power, moral leadership and ethical decision making.

The location for this final workshop was a studio in the theatre, which also doubles as a performance space. This final workshop started more formally, with an introduction by the lecturers who invited students to reflect on their learning thus far. Using fun in learning (Huffaker and West, 2005) was an important component of each workshop and the various exercises were presented as games. As the morning began, the theatre director asked the group to 'play and have real fun, but think about what you are learning and your ideas about wicked problems and their solutions, wicked or otherwise, about morality and ethics' (Author three). These themes formed the basis of the debriefing sessions, which happened at different points throughout the day.

The workshop consisted of seven different exercises, each of which explored a separate theme of ethical leadership. Our focus for this article is on the final activities of the workshop consisting of two small group improvisational activities. The first activity was a game called 'giants, wizards and elves', while the second involved collaboratively creating and presenting short performances about the collapse of Enron. Each activity was followed by a group discussion and debriefing. These activities were designed in such a way that they would encourage the students to drawn on the entire repertoire of drama skills they learnt over the three workshops and apply them to highly sensitive issues in critical management studies. 
'Giants, wizards and elves' is an improv activity designed to get students thinking about ethical decision-making and wicked problems through use of metaphor. It is similar to the 'paper, scissors, stone' game played by children, where one category outranks the other. Like 'paper, scissors, stone', there is an action associated with each category and they trump each other as follows: giants stamp on elves; elves crawl under wizards and wizards freeze the giants. The game is competitive. Students are split into two groups and face each other in long lines. There is a group decision about which character to use (giant, wizard or elf), battle lines are drawn and on a signal, the two groups perform their action. Whichever group wins the round is allowed to take one person from the other group and the bigger group at the end of a fixed number of rounds is the winner. As a reflection on wicked problems, the game is interesting because there are no right or wrong decisions; the outcome is a product of both groups' decisions and is thus dependent on context (Preparatory notes, Author Three. See Picture 2).

The two groups ( $X$ and $Y$ ) quickly got into the spirit of the game, huddling at far ends of the room so that their deliberations would not be overheard. Notes from the field diaries capture the immersion in the game, as well as the emotions that the competition provoked: Lots of scheming going on. Ys are confident and ready while the Xs are still in a huddle and looking uncertain. They all march 5 steps forward and on the count of 3 make their gesture. Surprisingly, the Ys retreated en masse back to the door and the Xs charged (to grab a captive). Their attitudes changed and now the $Y$ s are unsure while the Xs are confident. The Xs capture KP. The Ys capture TZ - all the women in the group grabbed her and dragged her along. TZ then tries to warn the Xs what gesture the Ys 
are choosing. Chaos on the next go as both groups think they've won. It's vicious! (Field notes, Author One. See Picture 3)

The students understood exactly what was required. Clearly the rules were up for grabs and each group had a clever justification for bending them. (Field notes, Author Three).

In the reflective diary written that night, Author One reflected on the 'unethical' behaviour that had emerged during the game:

As the game progressed, I noticed that both groups were subtly altering the rules. Sometimes they took two captives, captives did not transfer their loyalties but tried to reveal the chosen action to their old team and teams used multiple actions at once so that they could not be trumped. In the debrief that followed, Author Three sternly reminded the groups that 'The game is like life and business and leadership and ethics and morals. There were ethics guiding this game. They were: take only one person and only use one power'. Both groups had broken the game's rules and the groups offered various excuses for their actions, such as 'we needed fast decision-making' and 'the Ys were trying to trick us', while accusing their opponents of unethical behaviour ('The captives were committing treason. They were telling the other team our tactics'). There was a clamour of voices at the beginning of the debriefing; the students were very worked up and eager to justify their actions. Several of the most vocal speakers (two men and two women) were Chinese students who never spoke in class and therefore we had assumed that their language abilities were poor. How wrong we were (Field diary, Author One). 
There are two points to make about this game. The first is that it illustrates how improv activities can offer an alternative way of exploring complex theoretical material. Although the students had struggled with ethical leadership during the lecture, here they threw themselves into the activities first, then slowly began to absorb the implications of their actions in the discussion that followed. Guided by expert facilitation, the groups experienced a range of reactions including outrage, joy about winning and embarrassed silence as individuals realised the implications of their actions. The 'dry' academic literature on wicked problems was brought to life by an activity where participants could construct meaning for themselves through interaction with their peers (Corsun et al., 2006; Gagnon et al., 2012) and engage in collaborative learning (Light and Cox, 2001; Valiente, 2008):

I was overwhelmed to see the students so animated by a topic which in class did not trigger much collective or individual response, maybe one or two questions at the end of the session. At the theatre, the wicked problems exercise triggered serious debate followed by laughter, frustration, and determination to keep trying until a suitable solution could be found (Field notes, Author Two).

The second point relates to the academic author's preconceptions and unexplored assumptions about our international students:

This experiential work with the students made me realise was that I was in their shoes more than 20 years ago when I came to study for a DPhil in management in the UK. I was equally quiet, my spoken English was not as good as my written one and if it weren't for the one to one tutorial system at Oxford, I probably would have not had the opportunity to find my voice. It was the human connectivity and the safety of the one to one tutorial system that helped me flourish in the same way in which the 
neutral space of the theatre and the experiential exercises made my students come out of their shells and find their voice (Reflective diary, Author Two).

We had readily equated silence in class with poor English language skills, yet in the heat of the game's 'battle', international students were communicating fluently with each other and passionately justifying their actions to us in clear fluent English. This forced us to reconsider our easy assumptions about class participation and to acknowledge that we were often guilty of unreflectively reproducing Western educational paradigms (Simpson et al., 2010; Currie, 2007; Turner, 2006).

The second improv activity built on 'Giants, wizards and elves'. The two groups were asked to apply the game's rules in their interpretation of events in the Enron case study. The director's preparatory notes ask:

What were the giants, wizards \& elves represented by? It's not just inside the organisation. Who is who? Why did it collapse? Groups have to name each idea and come up with a symbol for each of them.

Once symbols are chosen, each group has to create short non-verbal performances, showing each symbol and how they interacted. The symbols reflected their interpretation of Enron's collapse and all members of the group had to take part in the presentation. A theatre practitioner stayed with each group to help them coordinate their ideas, but the three authors left the studio so that students would be less self-conscious in their planning and deliberations. Presentations took place on the stage, with the authors and nonperforming group sitting in the audience. A debriefing followed each performance, with the performers then explaining their actions and audience also interpreting the gestures. This collective sense-making (Corsun et al. 2006; Moshavi, 2001) was a significant moment 
during the activity, as the performers and audience often had different interpretations of the actions. The performers often decided that some of the audience's interpretations were 'better' than their original ideas.

The first group stood in a long, straight line and created four actions rather than three: rubbing fingers together, a train motion, binoculars and pouring something into their hands. $Q$ announces that they had 4 types. Co-operation: money makes profit, crazy beat (train) of employees, pouring salt into the hand is the customer and binoculars are the monitors. They reported that as they prepared the presentation, they began to reflect on how problems in Enron had occurred, asking themselves what was missing in the organisation. This is why they introduced a fourth symbol, that of the monitor who would oversee the actions of the company. The group discussion that followed focused on who the monitor should be, with suggestions such as regulators, leaders, employees and society being offered by the students (Field notes, Author One).

The second group arranged themselves in a semi-circle with one person apart from them, in the centre:

The three actions: Hands folded ( $L$ in the centre of a semi-circle, acting self-satisfied and arrogant), hands in chain (L leading) and fists in circle facing in, then raising fists. This group concentrated on organisational power structures. In the debriefing, they explained that the first action represented Enron's CEO, standing in the centre of the group with middle management arranged behind him in a semi-circle. They explained that they had originally planned to stand in a circle, but changed their minds at L's suggestion: 'He's in the centre as top manager. We were originally in a circle but $L$ suggested standing in a semi-circle to show arrogance and pride'. Their second action 
of hands in a chain represented the interconnections between managers and the organisation's strong culture. When asked to guess what the final action might symbolise, one of the audience suggested that it looked like a workers' union. The presenters agreed, saying that the idea was to 'unite together to do the task'. Like the previous group's creation of monitors, the trade union was presented as an alternative way of addressing Enron's structures and working practices, with students imagining an alternative reality at Enron had employees been unionised (Field notes, Author One. See Picture 4).

Both groups strayed from the brief by reinterpreting the rules to suit their understanding of the Enron case study. In the debriefing that followed, however, students demonstrated that they were moving from passive learners to empowered 'spect-actors' (Boal, 2008; Feagan and Rossitor, 2011; Monks et al., 2001). They were willing to discuss not just the actual case history, but also offered a range of alternative paths that the company could have chosen.

Their Enron presentations were filled with new insights which allowed me as an outsider to the management field to understand the complex dynamics which brought about the downfall of a giant (Reflective diary, Author Three).

The improv activities allowed them to explore and define their key themes (Huffaker and West, 2005), in a collaborative, non-judgemental setting (Stager Jacques, 2013; Moshavi, 2001). Rather than reproduce the classroom setting, where the students typically sat in national groups, at the theatre, these divisions were erased and normally quiet students spoke at length as well as taking part wholeheartedly into each and every performance. The students who were vocal in class appeared happy to make room for quieter voices to be heard: a sense of camaraderie and sharing was apparent. Moreover, the activity revealed 
that far from being passive learners, the students were engaging with the reading list, moving beyond the set texts to the additional readings:

During one of the exercises, one of students referred to a model of leadership that I had not taught in class, but was part of my rather long supplementary reading list. I was impressed (if not shocked) that this student went through the supplementary reading list in advance of coming to the theatre. (Reflective diary, Author Two).

\section{Discussion and conclusions}

To summarise then, drawing on drama techniques has become an established feature of management learning. Our project used improvisational techniques, inspired by the forum theatre of Boal (2008), to encourage students to develop creative, collaborative responses to problematic situations highlighted by critical management literature studied in the classroom. These techniques encouraged interaction and learning in a safe, nonconfrontational environment, where students could find their voice at a pace that suited their particular needs and abilities. In what follows, we reflect on our experiences of using drama as a pedagogical response to internationalisation, considering both the benefits and the harder lessons learned. We end by considering the disruptive and subversive role of experiential drama in management education.

When the project ended, we observed that the sense of camaraderie and sharedness developed at the theatre was brought back into the classroom. Students no longer worked in groups formed around national cultures but were happy to mix across cultures and their group discussions were more vivacious than before. Many of the Chinese students who were previously quiet began to ask questions during class, as well as offering comments 
during class discussions. Our own practice changed as well, as we found it much easier to relate to the quiet students and became more effective at encouraging creative responses from them. This was achieved by moving away from purely discursive ways of teaching to more experiential ones such as asking the students to draw images of leadership and then discussing them in groups or doing listening exercises which encouraged vocal students to be silent and quiet ones to speak up.

Our closer relationship with all students (UK and international) was made possible by the fact that theatre workshops created equality between us and them because the traditional classroom structure and hierarchy was temporarily disrupted. Rather than reproducing typical Western pedagogical approaches to learning (for example, student or teacher-led seminars and debates), the theatre released student imagination through the creation of 'as if' worlds (cf. Greene, 1995), promoted collective sense-making and co-creation of knowledge (Light and Cox, 2001) and we aimed to replicate this learning model in the classroom. Instead of promoting the most confident, articulate speakers, which often happens in seminars, our teaching methods encouraged 'listening, observing and selfawareness' (Stager Jacques, 2013: 251).

The project also forced us to confront our own pedagogical biases (Currie, 2007; Simpson et al., 2010; Turner, 2006), an experience which led to some uncomfortable reflections about how dismissive we had been about students' levels of engagement and their abilities. Although our overall memories of the workshops are positive and joyful, at various stages, the academic authors felt guilt, embarrassment and remorse when Author Three pointed out students' abilities that had not emerged in the classroom ('DZ was such a great leader today'; 'look at CW arguing her point - she's so confident'). As lecturers we were profoundly 
changed by this experience and we have returned to the classroom less judgemental and more open to creative, inclusive, non-linear approaches.

The learning derived from this project contributes useful insight to the literature on classroom internationalisation. UK business schools have almost universally adopted modularised programmes that promote self-contained, bite-sized learning. Creating experiential drama exercises that go against this dominant model involves a degree of pedagogical risk taking (Feagan and Rossiter, 2011), not least for the students who have been disciplined (Foucault, 1977) into becoming consumers of easily digestible nuggets of knowledge, but also for the lecturers who may not be keen or able to transcend the expert/student dichotomy and experiment with teaching methods which destabilise taken for granted hierarchies in the classroom. In this sense, drawing on the forum theatre tradition (Boal, 2008) represents a subversive move, as it disrupts the commoditised modular learning used in the majority of UK PGT programmes and replaces it with something more fluid and uncertain, that treats learning as an embodied, emotional and holistic experience.

Earlier in the paper, we compared improvisational theatre and outdoor management development (OMD) literatures, suggesting that they share a common interest in embodiment, play and exploratory learning, sensitising participants to the ways in knowledge can emerge in unpredictable ways (Hinchliffe, 2000; Taylor, 2012). This reflects our experiences during the workshops. OMD has been criticised, however, for not offering sufficient evidence of these benefits (Irvine and Wilson, 1994; Ibbetson and Newell, 1999) and, as one of our reviewers pointed out, OMD (and theatre) is site specific; there is no 
guarantee that the disruption of power relations will last. This is something we have wrestled with since the project finished. As Author One noted:

I'm getting a bit sick of colleagues asking me what difference it made. Everyone wants 'evidence', but they seem to want to hard scientific facts and figures. Nobody seems excited by the fact that the students (all of them - international, home, EU) are more confident when they come to my office hours (Reflective diary, Author One).

We also realised that the worlds of universities and theatre are often difficult to reconcile given their rigid timetables of teaching and performances. During the project, administrative issues such as room bookings, time slots and capacity were at times our prime concerns and what was intended as an emancipatory experiment in experiential drama was overshadowed by hands on management and pragmatic resource planning. By its nature, non-traditional inter-disciplinary teaching means that it is precarious and difficult to fit it within a highly-routinised, modularised, inflexible and cost-sensitive teaching environment. While these workshops instilled a sense of belongingness and camaraderie amongst the students as well as giving 'voice' to those who usually sat on the margin in the classroom, it is not easy to convince senior management that this way of teaching brings benefits to the students and should become more institutionalised. While we were able to secure a teaching innovation grant for this experiment, no formal commitment had been made to continue with this type of teaching, beyond the original grant.

Despite these reservations, our experience to date suggests that business schools with a large international cohort of students should work more closely with theatres which endorse a social agenda and an ethos of community engagement in order to learn from and reflect on the techniques used by such theatres to reach marginalised communities and 
individuals and give them a voice. Such techniques could then be applied in teaching management students in the classroom or in other environments to ensure the creation of trust amongst home and international students, a more equal participation in the learning process and even a reversal of the hierarchies between students and academics. As we have hopefully demonstrated, these techniques can help create a safe environment where students and academics can reflect on their own role in reproducing dominant discourses and try out ways in which such discourses can be disrupted to make room for alternative ways of learning which are more inclusive and experientially based.

\section{References}

Barry D and Meisiek S (2010) Seeing More and Seeing Differently: Sensemaking, Mindfulness and the Work-Arts. Organization Studies 31(11): 1505-1530.

Baruch Y (2006) Role-play Teaching: Acting in the Classroom. Management Learning 37(1): 43-61.

Beirne M and Knight S (2007) From Community Theatre to Critical Management Studies: A Dramatic Contribution to Reflective Learning? Management Learning 38(5): 591-611.

Boal A (2008) Theatre of the Oppressed. London: Pluto Press.

Boje MD, Gardner CL and Smith WL (2006) (Mis)using Numbers in the Enron Story. Organizational Research Methods 9(4): 456-474.

Boje MD, Luhman JT and Cunliffe A (2003) A Dialectic Perspective on the Organization Theatre Metaphor. American Communication Journal 6(2). 
Boje MD and Rosile GA (2003) Life Imitates Art: Enron's Epic and Tragic Narration. Management Communication Quarterly 17(1): 85-125.

Boje MD, Rosile GA, Durant RA and Luhman JT (2004) Enron Spectacles: A Critical Dramaturgical Analysis. Organization Studies 25(5): 751-774.

Broderick A and Pearce G (2001) Indoor Adventure Training: A Dramaturgical Approach to Management Development. Journal of Organizational Change Management 14(3): 239-252. Cheng R (2013) A Non-Native Student's Experience on Collaborating with Native Peers in Academic Literacy Development: A Sociopolitical Perspective. Journal of English for Academic Purposes 12(1): 12-22.

Corsun DL, Young CA, McManus A and Erdem M (2006) Overcoming Managers' Perceptual Shortcuts through Improvisational Theater Games. Journal of Management Development 25(4): 298-315.

Crose B (2011) Internationalization of the Higher Education Classroom: Strategies to Facilitate Intercultural Learning and Academic Success. International Journal of Teaching 23(3): 388-395.

Cunliffe AL (2009) The Philosopher Leader: On Relationalism, Ethics and Reflexivity: A Critical Perspective on Teaching Leadership. Management Learning 40(1): 87-101.

Currie G (2007) 'Beyond Our Imagination': The Voice of International Students on the MBA. Management Learning 38(5): 539-556.

Daskalaki M (2012) Personal Narratives and Cosmopolitan Identities: An Autobiographical Approach. Journal of Management Inquiry 21(4): 430-441. 
Elliott C and Robinson S (2012) MBA Imaginaries: Projections of Internationalization. Management Learning 43(2): 157-181.

Elm DR and Taylor SS (2010) Representing Wholeness: Learning via Theatrical Productions. Journal of Management Inquiry 19(2): 127-136.

Feagan R and Rossiter K (2011) University-Community Engagement: A Case Study using Popular Theatre. Education + Training 53(2/3): 140-154.

Foucault M (1977) Discipline and Punish: The Birth of the Prison. London: Penguin Books Ltd. Gabriel Y and Griffiths DS (2008) International Learning Groups: Synergies and Dysfunctions. Management Learning 39(5): 503-518.

Gagnon S (2008) Compelling Identity: Selves and Insecurity in Global, Corporate Management Development. Management Learning 39(4): 375-391.

Greene M (1995) Releasing the Imagination: Essays on Education, the Arts and Social Change. San Francisco: Jossey Bass.

Grint, K. (2005). 'Problems, Problems, Problems: The Social Construction of Leadership'. Human Relations 58, 1467-94.

Grint, K. (2007). 'Questions of Leadership: Aristotle, Learning and Leadership', Leadership, 3, 211-26.

Griffiths DS, Winstanley D and Gabriel Y (2005) Learning Shock: The Trauma of Return to Formal Learning. Management Learning 36(3): 275-297.

Hinchliffe S (2000) Performance and Experimental Knowledge: Outdoor Management Training and the End of Epistemology. Environment and Planning D: Society and Space 18(5): 575-595. 
Huffaker JS and West E (2005) Enhancing Learning in the Business Classroom: An Adventure with Improv Theater Techniques. Journal of Management Education 29(6): 852-869. Ibbetson A and NEWELL S (1999) A Comparison of a Competitive and Non-competitive Outdoor Management Development Programme. Personnel Review 28(1): 58-76. Irvine D and WILSON JP (1994) Outdoor Management Development - Reality or Illusion? Journal of Management Development 13(5): 25-37.

Kelemen $\mathrm{M}$ and Peltonen T (2001) Ethics, morality and the subject: the contribution of Zygmunt Bauman and Michel Foucault to 'postmodern' business ethics. Scandinavian Journal of Management 17(2): 151-166.

Kelly P and Moogan Y (2012) Culture Shock and Higher Education Performance: Implications for Teaching. Higher Education Quarterly 66(1): 24-46.

Lesavre L (2012) Are Theatre and Business Links Relevant? A Conceptual Paper and a Case Study. Journal of Management Development 31(3): 243-252.

Light G and Cox R (2001) Learning and Teaching in Higher Education: The Reflective Professional. London: Paul Chapman Publishing.

May RAB and Pattillo-McCoy M (2000) Do You See What I See? Examining a Collaborative Ethnography. Qualitative Inquiry 6(1): 65-87.

McEvoy GM and Buller PF (1997) The Power of Outdoor Management Development. Journal of Management Development 16(3): 208-217.

Meisiek S (2004) Which Catharsis Do They Mean? Aristotle, Moreno, Boal and Organization Theatre. Organization Studies 25(5): 797-816.

Meisiek S and Barry D (2014) Theorizing the Field of Arts and Management. Scandinavian Journal of Management 30(1): 83-85. 
Monks K, Barker P and Ní Mhanacháin A (2001) Drama as an opportunity for learning and development. Journal of Management Development 20(5): 414-423.

Moshavi D (2001) 'Yes and...': Introducing Improvisational Theatre Techniques to the Management Classroom. Journal of Management Education 25(4): 437-449.

Pässilä AH, Oikarinen T and Harmaakorpi V (2013). Collective Voicing as a Reflexive Practice. Management Learning 46(1): 67-86.

Prichard C (2009) Three Moves for Engaging Students in Critical Management Studies. Management Learning 40(1): 51-68.

Rittel H and Webber M (1973). Dilemmas in a General Theory of Planning. Policy Sciences 4: 155-169.

Simpson R, Sturges J and Weight P (2010) Transient, Unsettling and Creative Space:

Experiences of Liminality through the Accounts of Chinese Students on a UK-Based MBA. Management Learning 41(1): 53-70.

Stager Jacques L (2013) Borrowing From Professional Theatre Training to Build Essential Skills in Organization Development Consultants. The Journal of Applied Behavioral Science 49(2): 246-262.

Stead V and Elliott C (2013) Women's leadership learning: A reflexive review of representations and leadership teaching. Management Learning 44(4): 373-394.

Stoudt B (2009) The Role of Language \& Discourse in the Investigation of Privilege; Using Participatory Action Research to Discuss Theory, Develop Methodology, \& Interrupt Power. The Urban Review 41(1): 7-28. 
Sun H and Richardson J (2012) Perceptions of Quality and Approaches to Studying in Higher Education: A Comparative Study of Chinese and British Postgraduate Students at Six British Business Schools. Higher Education 63(3): 299-316.

Sutherland I (2012) Arts-Based Methods in Leadership Development: Affording Aesthetics Workspaces, Reflexivity and Memories with Momentum. Management Learning 44(1): 2543.

Taylor SS (2013) Little Beauties: Aesthetics, Craft Skill, and the Experience of Beautiful Action. Journal of Management Inquiry 22(1): 69-81.

Taylor SS and Ladkin D (2009) Understanding Arts-Based Methods in Managerial Development. Academy of Management Learning and Education 8(1): 55-69.

Taylor SS and Ladkin D (2014) Leading as Craft-work: The Role of Studio Practices in Developing Artful Leaders. Scandinavian Journal of Management 30(1): 95-103.

Tourish D and Vatcha N (2005) Charismatic Leadership and Corporate Cultism at Enron: The Elimination of Dissent, the Promotion of Conformity and Organisational Collapse. Leadership 1(4): $455-480$.

Turner Y (2006) Chinese Students in a UK Business School: Hearing the Student Voice in Reflective Teaching and Learning Practice. Higher Education Quarterly 60(1): 27-51. Turner Y (2009) 'Knowing Me, Knowing You,' Is There Nothing We Can Do?: Pedagogic Challenges in Using Group Work to Create an Intercultural Learning Space. Journal of Studies in International Education 13(2): 240-255.

Valiente C (2008) Are Students Using the 'Wrong' Style of Learning? Active Learning in Higher Education 9(1): 73-91. 
Weick K, Sutcliffe KM and Obstfeld (2005) Organizing and the Process of Sensemaking. Organization Science. 16(4): 409-421. 